\title{
A single centre experience in the management of undescended testes
}

\section{Singh L R. ${ }^{1}$, Gojen Singh K. ${ }^{2}$, Mackson Singh N. ${ }^{3}$, Singh Salam S. ${ }^{4}$, Chinglensana L. ${ }^{\text {, Keshorjit }}$ Singh I. ${ }^{\text {** }}$}

DOI: https://doi.org/10.17511/ijpr.2020.i01.02

\footnotetext{
1 Ramesh Singh L, Associate Professor, Department of Surgery, Regional Institute of Medical Sciences, Imphal, Manipur, India.

$\mathbf{2}$ Khuraijam Gojen Singh, Associate Professor, Department of Surgery, Regional Institute of Medical Sciences, Imphal, Manipur, India.

3 Nongmaithem Mackson Singh, Senior Resident, Department of Surgery, Regional Institute of Medical Sciences, Imphal, Manipur, India.

4 Sunilkumar Singh Salam, Associate Professor, Department of Surgery, Regional Institute of Medical Sciences, Imphal, Manipur, India.

$\mathbf{5}$ Laitonjam Chinglensana, Associate Professor, Department of Surgery, Regional Institute of Medical Sciences, Imphal, Manipur, India.

6* Irom Keshorjit Singh, Associate Professor, Department of Paediatric Surgery Unit, Regional Institute of Medical Sciences, Imphal, Manipur, India.
}

Introduction: Undescended testes (UDT) is one of the most common congenital anomalies of the urogenital system. In spite of its common occurrence, lots of variations are still reported regarding the time of surgery, mode of investigation and surgery. The present study tried to report the single centre experience of management of UDT. Materials and Methods: The data of patients with UDT including time of presentation, time of surgery, position of testes, investigations, associated urogenital anomalies, complications were collected over a period of 9 years and 6 months and analysed. Results: A total of 118 children were recorded of which the testes of 6 infants became descended before the age of 6 months. Out of the remaining, 112 children, 24 children had bilateral UDT, 24 children had nonpalpable testes (NPT). Ultrasound could locate 19 NPT pre-operatively. Maximum children were operated between 6 months to 1 year in 43 children (38.39\%). Laparoscopy was done for intra-abdominal testes and NPT whose locations could not be located by US and the rest by open inguinal exploration. Four children had pre-operative complications with obstructed inguinal hernias ( 2 cases) and testicular torsion ( 2 cases). Conclusion: Majority of the children were being operated before the age of 1 year and US is a good non-invasive to effectively locate the NPT.

Keywords: Cryptorchidism, Nonpalpable testes, Orchidopexy, Undescended testes

\section{Corresponding Author}

Irom Keshorjit Singh, Associate Professor, Department of Paediatric Surgery Unit, Regional Institute of Medical Sciences, Imphal, Manipur, India. Email: driksingh@yahoo.co.in

\section{How to Cite this Article}

Singh LR, Singh KG, Singh NM, Salam SS, Chinglensana $L$, Singh IK. A single centre experience in the management of undescended testes. Pediatric Rev Int J Pediatr Res. 2020;7(1):8-13.

Available From

https://pediatrics.medresearch.in/index.php/ijpr/arti cle/view/563
To Browse

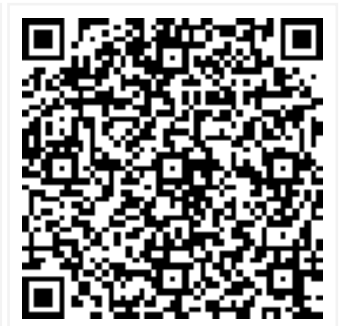

Manuscript Received 2019-12-28

Conflict of Interest No
Review Round 1 2019-01-08

Funding

Nil
Review Round 2 2019-01-14

Ethical Approval Yes
Review Round 3

Plagiarism X-checker $9 \%$
Accepted 2019-01-17

Note

(c) 2020 by Ramesh Singh L, Khuraijam Gojen Singh, Nongmaithem Mackson Singh, Sunilkumar Singh Salam, Laitonjam Chinglensana, Irom Keshorjit Singh and Published by Siddharth Health Research and Social Welfare Society. This is an Open Access article licensed under a Creative Commons Attribution 4.0 International License https://creativecommons.org/licenses/by/4.0/ unported [CC BY 4.0]. 


\section{Introduction}

Cryptorchidism is defined as the absence of at least one testis in the scrotum [1]. Undescended testis is a very common congenital anomaly of the urogenital system and the most common disorder in paediatric surgery, affecting up to $30 \%$ of preterm and $3 \%$ of term infants worldwide [2-4]. Testicular decent takes place at two stages under control of insulin-like hormone 3 between 8 and 15 weeks of development [5] and androgens facilitating inguinoscrotal migration afterwards [6]. Unclear definitions and conflicting results from the medical literature make its management still a muchdebated issue $[7,8]$.

UDT commonly refers to a testis which is present in an extra-scrotal position, but it may lead to identification of an absent testis. The absent testis is usually due to spermatic cord torsion or vascular accident leading to vanishing testis during development. The main reasons for warranting treatment of UDT include increased risk of impairment of fertility potential, testicular malignancy, other complications like torsion of the testis and incarceration of hernias. The current recommendation of therapy is orchidopexy or surgical reposition of the testis within the scrotal sac while hormonal therapy has fewer advocates [9].

The successful scrotal positioning of an UDT may reduce but does not prevent the potential of longterm complications. According to published guidelines, the surgical treatment of UDT should be done between the age 6 months to 18 months without any adjuvant hormonal treatment as the advantage of hormonal treatment in inducing the descent of UDT or improving the fertility potential is not uniform in different studies. In spite of the published surgical and treatment guidelines, major chunk of these children is being managed beyond the ideal treatment window [9].

There has been lots of deviations about the timing of surgery, mode of investigation for nonpalpable testes (NPT) and outcome following surgical treatment. Even in the developed countries, the adherence to the guideline timeline for surgery is still poor [10-13]. Different authors and institutes still resort to investigations like US, MRI, CT scan, laparoscopy, venogram, arteriogram etc even though US is the most accepted first line of investigation for locating nonpalpable testes [1422].
The present study tried to report the clinical profile of our patients with undescended testes, timing of surgery, mode of treatment and clinical outcome during the follow up and if they conform with the existing guidelines of managing the UDT.

\section{Material and Methods}

Setting: The present had collected the patient's data with undescended testes reported to the paediatric surgery clinic during the study period. Those children with UDT treated completely with surgical intervention were retrospectively collected and analysed for the study.

Duration of Study: Children presented during a period of 9 years and 6 months, from 2010 January and 2019 July were included in the study. The information about the patient profile were collected including the age at presentation, age at the time of surgery, location of testis, mode of treatment, associated urogenital anomalies, outcome measured by a viable scrotal testis.

Careful clinical examination was done by paediatric surgeon in the supine position, with the lower half of the body undressed. The inguinal region and scrotum were carefully examined with the fingertips of a warm hand. The examiner first carefully palpate both the scrotum up to the external inguinal ring for any presence of palpable testes. If the testis was not palpable, the examiner's right hand fingers runs down in a sweeping movement from the deep inguinal ring to milk out the testes lying near the deep ring towards the superficial ring and scrotum, at the same time the left hand index finger placed at the deep ring to prevent slippage of the testis to the abdomen.

When the deep ring is still blocked by the left hand, the inguinal canal, external ring and root of the scrotum are carefully examined by the right hand for any normal volume or a small atrophic testis. If the testis was still not palpable, the patients were subjected to Ultrasound (US) by the radiologists. The findings of the US including the location of the testes, volume, associated anomaly if any were recorded. The intra-operative findings, operative complications and the follow up outcome of the operated testes were recorded.

Surgical Treatment: Boys with the palpable UDT and NPT located in the inguinal canal and internal ring were operated by inguinal exploration and orchidopexy done in the sub-dartos pouch. 
Intra-abdominal testes and NPT that could not be located by US were operated with laparoscopy and completed the procedure by a single stage orchidopexy or 2 stage Fowler-Stephens orchidopexy depending on the final location identified by laparoscopy. A non-viable testis during the surgery was removed.

\section{Inclusion criteria}

All boys with UDT who presented to the paediatric Surgery Clinic during the study period were included in the study.

\section{Exclusion criteria}

Those children who have not been operated or who have not turn up for further management after the diagnosis were not included in the study.

Data analysis was done by mean and percentage only. The statistical analysis of the data was done using Statistical Package for the Social Sciences (SPSS) V21.0.

Ethical clearance and permission for using the hospital data was obtained from the institute's Ethical Committee.

\section{Results}

During the study period, a total of 118 patients with undescended testes were presented to the paediatric surgery clinic. Twenty-eight children presented with undescended testis before the age of 6 months and neonatal period and they were followed up till the age of 6 months without any medication. Out of the total 28 children with UDT, 6 testes became scrotal testis or descended during the follow up. A total of 112 children were still having after the age of 6 months and were intervened surgically.

Table-1: Age distribution of undescended testes at the time of surgery.

\begin{tabular}{|l|l|}
\hline \multicolumn{1}{|c|}{ Age group (at surgery) } & \multicolumn{1}{c|}{ No of patients } \\
\hline 6 months-1 year & $43(38.39 \%)$ \\
\hline 1 year-2 years & $15(13.39 \%)$ \\
\hline 2 years-3 years & $7(6.25 \%)$ \\
\hline 3 years-4 years & $8(7.14 \%)$ \\
\hline 4 years-5 years & $7(6.25 \%)$ \\
\hline$>5$ years & $32(28.57 \%)$ \\
\hline Total & $112(100 \%)$ \\
\hline
\end{tabular}

The age of the children at the time of surgery varied from 6 months to 12 years with the mean of $3.28 \pm$ 3.18 years.
Maximum children were operated between the age group of 6 months to 1 years comprising 43 (38.39 $\%$ patients. Almost $52 \%$ operated before 2 years of age and $32(28.57 \%)$ were operated after the age of 5 years.

Thirty-four (30.36\%) children had left UDT, 54 $(48.21 \%)$ had right UDT and 24 bilateral testes, totalling 136 testes which were undescended. Out of the 112 patients, 58 boys had nonpalpable testes (NPT) after the examination by the paediatrician or general practitioner at the time of referral. These 58 boys were further re-examined by the paediatric surgeon and 34 (58.6\%) of them were palpable.

The remaining 24 boys with NPT were subjected to US and 19 (79\%) of them could be located by the US and 5 could not be identified. Non palpable testes were identified at the deep inguinal ring in 10 children, inguinal canal in 5, intra-abdominal in 4 and 5 were not visualised in US. All the 19 testes which were visible in US were actually located at the place as predicted by US during the surgery. But it failed to demonstrate 2 testes in abdomen, 1 in deep ring, 1 in inguinal canal and 1 was actually anorchid.

Out of the 112 palpable testes, 82 (60.29\%) were inguinal canal, $19(13.97 \%)$ in superficial inguinal ring and 11 ( $8 \%$ ) in root of the scrotum. 24 (17.65 $\%)$ testes were not palpable. All the palpable testes were operated by an inguinal incision and nonpalpable testes (NPT) were operated by inguinal incision or laparoscopy depending on the localised position in US i.e. if the testes are intra-abdominal in position or not visualised, laparoscopy was done.

There were total 6 cases of intra-abdominal testes after laparoscopy. One of the intra-abdominal testes was a spleno-gonadal fusion on biopsy which was removed because of the suspicion of tumour transformation. another 1 was a mature teratoma which had gone torsion at the age of 6 months, 1 was anorchia and another 3 operated by laparoscopic 2 stage Fowler-Stephens orchidopexy including 1 atrophic testis.

All the patients with undescended testes located in the internal ring, inguinal canal, root of the scrotum had patent processus vaginalis except for patients with intra-abdominal testes. 18 patients had clinical hernia on the ipsilateral side and 5 on the contralateral side. Five patients were associated with hypospadias. Only 4 children (2.9\% of the total testicular units) developed complications with obstructed hernia ( 2 cases) and testicular torsion 
( 2 cases) before the surgery for which they needed emergency surgery.

After the surgical intervention, 5 patients had minor complications like 1 superficial wound infection, 3 scrotal hematoma, 1 testicular atrophy during the follow up after orchidopexy. The viable testes before the surgery had viable scrotal testes in the follow up except for 1 testis which became atrophic. Preoperatively, 14 patients had a smaller testis as compared to the normal contralateral testis.

\section{Discussion}

The prevalence of the undescended testes (UDT) may be as high as $30 \%$ of the preterm and $3 \%$ of the term babies [2-4] In our series, bilateral UDT was $21.43 \%$ of the children which is similar to reported literature of $10-20 \%$ of cases [23] and left side constituted $30.36 \%$ and right side were in 48 $\%$. Berkowitz et al showed that the incidence of cryptorchidism in 6935 new-born boys declined from $3.7 \%$ at birth to $1 \%$ by 3 months and remained constant at one year of age [23]. Accordingly, most of the UDT will spontaneously descend by three months of age $[4,23]$. However, boys with a small or poorly developed scrotum and those with hypospadias are more likely to be cryptorchid at three months of age [4]. In the present study, no hormonal therapy was used and only 6 children (5\%) had spontaneous descent in the 1 st 6 months of life.

The AUA Guideline published in August 2014 noted that there were no studies on long term fertility outcomes following hormonal therapy alone and recommended not to use hormones before the surgery to induce descent of testes or to improve the fertility outcome [4,9]. According to the American Urological Association, children with UDT should be followed till the age of 6 months for spontaneous descent and if they fail to descent, should be operated in the next 1 year [9].

In Germany, the first official treatment guideline for UDT from 1999 targeted orchidopexy to be performed within the first two years of life. In 2009 this guideline recommendation was modified, indicating that operative treatment has to be completed by the end of the first year of life [24]. Even though the guidelines laid down the timeline for operating the UDT varied between the age of 6 months and 18 months, some authors advocated an early intervention to avoid complications and testicular tissue loss [25].
Ibrahim et al reported 10 out of 18 patients (55.5\%) who had complicated UDT including torsion and incarcerated hernias were below the age of 6 months, advocating orchiopexy, as early as 3 months of age, may reduce the incidence of these complication [25] Moreover, unilateral cryptorchid testes operated on at 9 months grew better than non-operated testicles in the control group [9] and testicles operated on at 3 years of age [4].

Treatment in the second semester of life aims to prevent histological changes and is not associated with more complications in the hands of experienced paediatric surgical teams than when performed later in life $[9,26]$. Cryptorchidism is best diagnosed clinically and treated by surgical orchidopexy at the age of 6-12 months or within 6-18 months without routine biopsy $[9,10,26]$. If no testis is palpable, or if other signs of hypo-virilisation such as hypospadias are present, chromosomal sex and hormonal status must be assessed. In spite of the recommendations to performed the orchidopexy before 1 year, a large number of children are still operated after the age of 1 year in many series as high as $90 \%$ [10-13].

Hensel reported that only $8 \%$ received orchidopexy in the first year of life from 2003 to 2008 and $9 \%$ from 2010 to 2012. Even in the hospitals where a paediatric surgeon was available only $6 \%$ (between 2003 - 2008) and $10 \%$ (between 2010 - 2012) were operated before 1 year and $3 \%$ without a paediatric surgeon in both the time intervals. In hospitals with paediatric surgery departments, significantly more children received surgical treatment according to guideline recommendations; both before (29\% vs. $17 \%$ ) as well as after modification of the guideline ( $10 \%$ vs. $3 \%$ ).

In a nationwide survey of primary care paediatricians about the primary treatment modality to be initiated in patients with UDT, $82 \%$ and $17 \%$ of the paediatricians felt conservative and surgical procedure respectively should be initiated. Between 2003 to 2008, $78 \%$ of the patients were not operated according to the medical guideline, namely, after their second year of life. After modification of the guideline recommendation $95 \%$ of the orchidopexies were performed after the first year of life [10].

Höfling et al [11] in a German university hospital, as well as with data from an Austrian study [12] from 2010 reported a similar divergence from the recommendation. 
Similarly, in the USA, only $18 \%$ of the patients with UDT received orchidopexy before the age of 2 and $43 \%$ were operated before reaching the age of 3 years between 1999 and 2008 [13] In the present series also only 43 boys ( $38.39 \%)$ were operated between the age of 6 months - 1 year and 15 boys $(13.39 \%)$ between the age of 1 year and 2 years contributing almost $52 \%$ of children being operated before the age of 2 years which is very much higher as compared to other studies. The timing of surgical intervention is very much influenced by the knowledge of the paediatrician and general practitioner who referred the case to the paediatric surgeon.

Our centre has very effectively used US to locate NPT as a modality of choice as recommended by AUA guidelines with high positive predictive value ( $100 \%$ in visualised abdominal, internal ring and inguinal testes) and overall accuracy rate as high as $83.33 \%$ in locating the NPT. Different authors have reported different accuracy levels ranging from 18 $99 \%[16,17,19]$.

Even though, some authors had used initial inguinal incision for NPT, laparoscopy has become standard and best way in the diagnosis and treatment of nonpalpable testes and intra-abdominal testes $[14,15,22,27]$. In the present study also all the boys who were referred to the paediatric surgeon before the age of 6 months were operated between the age of 6 months to 1 year if they were not descended spontaneously and open inguinal exploration was done for palpable testes and laparoscopy for intra-abdominal testes and nonvisualised NPT in US.

Testicular size is not a predictor of sperm concentration values or of paternity chances [28]. So, every attempt should be made to fix the testes to the scrotum however small they may be for a possible fertility benefit.

The present study strengthened the evidence that all the palpable testes should be explored through the inguinal approach, US is a good non-invasive technique for locating the NPT with high accuracy and laparoscopy reserved for abdominal testes and in whom testes could not be located in US. But the current study could not give any information about a better and more accurate investigation in the preoperative stage for locating NPT as other modalities have not been done and compared with. Moreover, the long-term effects of testicular growth and fertility could not be evaluated in the present study.
There is a need for more prospective case control studies and long term follow up to find out the advantages of operating at the early age i.e. 6 months to 18 months in testicular growth and fertility.

\section{Conclusion}

All boys with UDT should be followed till the age of 6 months, if no spontaneous descent then should be operated between 6 months to 18 months for a maximum fertility benefit. Ultrasound is a very good modality for locating a non-palpable testis. Laparoscopy is reserved for intra-abdominal testes and non-visualised NPT in US.

\section{What the study adds to the existing knowledge?}

Moreover, it is an important need to educate or interact with the paediatricians and general practitioners about the accepted guidelines of timing of intervention, benefits of timely intervention, potential dangers of delaying the surgery to increase the compliance of early referral. There is a need for a long term follow up till adulthood for the fertility outcome and malignancy developing in the later age of life.

\section{Author's contributions}

All the authors have contributed during the work up, management of the children as well as the collection of the data, analysis and writing of the manuscripts at different capacities.

\section{Acknowledgement}

The authors would like to acknowledge and thank the children and parents who have given them the opportunity to examine them and allow to use their medical records for scientific use. The authors further thank the hospital authority, the institute and ethical committee who has given them the permission of the study.

\section{Reference}

01. Cortes D. Cryptorchidism- aspects of pathogenesis, histology and treatment. Scand J Urol Nephrol Suppl. 1998;196;1-54. [Crossref][PubMed] [Google Scholar] 
02. Barthold JS, Gonzalez R. The epidemiology of congenital cryptorchidism, testicular ascent and orchiopexy. J Urol. 2003;170(6)2396-401. doi: 10.1097/01.ju.0000095793.04232.d8 [Crossref] [PubMed][Google Scholar]

03. Virtanen $H E$, Bjerknes $R$, Cortes $D$, Jorgensen $N$, Rajpert-De Meyts E, Thorsson AV, et al. Cryptorchidism- classification, prevalence and longterm consequences. Acta Paediatr. 2007;96(5)611616. doi: 10.1111/j.1651-2227.2007.00241.x [Crossref][PubMed][Google Scholar]

04. John Radcliffe Hospital Cryptorchidism Study Group. Cryptorchidism- a prospective study of 7500 consecutive male births, 1984-8. Arch Dis Child. 1992;67(7)892-899. doi: 10.1136/adc.67.7.892 [Crossref][PubMed][Google Scholar]

05. Bay K, Main KM, Toppari J, Skakkebaek NE. Testicular descent- INSL3, testosterone, genes and the intrauterine milieu. Nat Rev Urol. 2011;8:187196. doi: 10.1038/nrurol.2011.23 [Crossref] [PubMed][Google Scholar]

06. Hutson JM. Journal of Pediatric SurgerySponsored Fred McLoed Lecture, Undescended testis- the underlying mechanisms and the effects on germ cells that cause infertility and cancer. J Pediatr Surg. 2013;48(5)903-908. doi: 10.1016/j.jpedsurg.2013.02.001 [Crossref] [PubMed][Google Scholar]

07. Kaplan GW. Nomenclature of cryptorchidism. Eur J Pediatr. 1993;152(2)S17-S19. doi: 10.1007/bf02 125427 [Crossref][PubMed][Google Scholar]

08. Stang A, Ahrens W, Bromen K, Baumgardt-Elms C, Jahn I, Stegmaier C, Krege S, Jöckel KH. Undescended testis and the risk of testicular cancerimportance of source and classification of exposure information. Int J Epidemiol. 2001;30(5)1050-1056. doi: $10.1093 / i j e / 30.5 .1050 \quad$ [Crossref][PubMed] [Google Scholar]

09. Kolon TF, Herndon CD, Baker LA, Baskin LS, Baxter CG, Cheng EY et al. Evaluation and treatment of cryptorchidism- AUA guideline. J Urol. 2014;192(2)337-345. doi: 10.1016/j.juro.2014. 05.005 [Crossref][PubMed][Google Scholar]

10. Hensel KO, Caspers T, Jenke AC, Schuler E, Wirth S. Operative management of cryptorchidismguidelines and reality - a 10-year observational analysis of 3587 cases. BMC Pediatrics. 2015;15;116. doi: 10.1186/s12887-015-0429-1 [Crossref][PubMed][Google Scholar]
11. Hoefling $K$, Sperling $P$, Meyer T. [Time of Operative Treatment of Maldescensus Testis in Childhood - Wishes and Reality]. Zentralbl Chir. 2014;139(6)627-631. doi: 10.1055/s-00321315123 [Crossref][PubMed][Google Scholar]

12. Springer A, Huber $C$, Reck CA, Fengler $D$, Horcher E. Delayed referral despite appropriate knowledge in cryptorchidism as a cause of delayed orchidopexies in Austria. Klin Padiatr. 2010;222(4)248-251. doi: 10.1055/s-00301248260 [Crossref][PubMed][Google Scholar]

13. Kokorowski PJ, Routh JC, Graham DA, Nelson CP. Variations in timing of surgery among boys who underwent orchidopexy for cryptorchidism. Pediatr. 2010;126;e576-582. doi: 10.1542/peds.2010-0747 [Crossref][PubMed][Google Scholar]

14. Fahlenkamp D, Rassweiler J, Fornara P, Frede T, Loening SA. Complications of laparoscopic procedures in urology- experience with 2,407 procedures at 4 German centers. J Urol. 1999;162(3 Pt 1)765-770. doi: 10.1097/00005392-19990901000038 [Crossref][PubMed][Google Scholar]

15. Thorup JM, Cortes D, Visfeldt J. Germ cells may survive clipping and division of the spermatic vessels in surgery for intraabdominal testes. J Urol. 1999;162(3 Pt 1)872-874. doi: 10.1097/00005392199909010-00080 [Crossref][PubMed][Google Scholar]

16. Graif M, Czerniak A, Avigad I, Strauss S, Wolfstein I, Itzchak Y. High-resolution sonography of the undescended testis in childhood- an analysis of 45 cases. Isr J Med Sci. 1990;26(7)382-385. [Crossref][PubMed][Google Scholar]

17. Elder JS. Ultrasonography is unnecessary in evaluating boys with a nonpalpable testis. Pediatr. 2002; 110;748-751. doi: 10.1542/peds.110.4.748 [Crossref][PubMed][Google Scholar]

18. Nguyen HT, Coakley F, Hricak H. Cryptorchidismstrategies in detection. Eur Radiol. 1999;9;336-343. doi: 10.1007/s003300050676 [Crossref][PubMed] [Google Scholar]

19. Kullendorff CM, Hederstrom E, Forsberg L. Preoperative ultrasonography of the undescended testis. Scand J Urol Nephrol. 1985;19(1)13-15. doi: 10.3109/00365598509180215 [Crossref][PubMed] [Google Scholar] 
20. Pekkafali MZ, Sahin C, Ilbey YO, Albayrak S, Yildirim S, Basekim CC. Comparison of ultrasonographic and laparoscopic findings in adult nonpalpable testes cases. Eur Urol. 2003;44(1)124127. doi: 10.1016/s0302-2838(03)00145-3 [Crossref][PubMed][Google Scholar]

21. Hrebinko RL, Bellinger MF. The limited role of imaging techniques in managing children with undescended testes. J Urol. 1993;150(2 pt 1)458460. doi: 10.1016/s0022-5347(17)35510-6 [Crossref][PubMed][Google Scholar]

22. Gapanya C, Freya P, Cachatb F, Gudinchetc F, Jichlinskie P, Meyrata B, Ramseyera P, Theintzd G, Burnandf B. Management of cryptorchidism in children- guidelines. Swiss Med Wkly. 2008;138(3334)492-498. [Crossref][PubMed][Google Scholar]

23. Berkowitz GS, Lapinski RH, Dolgin SE, Gazella JC, Bodian CA, Holzman IR. Prevalence and natural history of cryptorchidism. Pediatr. 1993;92(1)44-49. [Crossref][PubMed][Google Scholar]

24. Kinderchirurgie DGf. Leitlinien KinderchirurgieHodenhochstand - Maldeszensus testis, 2009. AWMF. 2009. Register No 006-022. Available at: www.awmf.org/leitlinien/detail/II/ 006-022.htm/ [Crossref][PubMed][Google Scholar]
25. Ibrahim AHM, Al-Malki TA, Ghali AM, and Musalam AO. Undescended Testes- Do We Need to Fix Them Earlier?. Ann Pediatr Surg. 2005;1(1)2125. [Crossref][PubMed][Google Scholar]

26. Lee PA. Fertility after cryptorchidismepidemiology and other outcome studies. Urol. 2005;66(2)427-431.

doi: 10.1016/j.urology.2005.01.017 [Crossref][PubMed] [Google Scholar]

27. Snodgrass W, Chen K, Harrison C. Initial scrotal incision for unilateral nonpalpable testis. J Urol. 2004;172(4)1742-1745.

doi: 10.1097/01.ju.0000140211.71113.58 [Crossref] [PubMed][Google Scholar]

28. Kollin C, Hesser $U$, Ritzen EM, Karpe B. Testicular growth from birth to two years of age, and the effect of orchidopexy at age nine months- a randomized, controlled study. Acta Paediatr. 2006;95(3)318-324. doi: 10.1080/08035250500423812 [Crossref][PubMed] [Google Scholar] 